\title{
Diagnostic Accuracy of Clinical Tests in Detecting Rotator Cuff Pathology
}

\author{
Helen Razmjou ${ }^{1,2,3 *}$, Monique Christakis ${ }^{4,5}$, Tim Dwyer ${ }^{6,7}$, Varda van Osnabrugge ${ }^{1}$, Patrick Henry ${ }^{6,8}$, Diane Nam ${ }^{6,8}$ \\ and Richard Holtby ${ }^{6,8}$
}

${ }^{1}$ Holland Orthopedic \& Arthritic Centre, Rehabilitation Department, Sunnybrook Health Sciences Centre, Toronto, Canada

${ }^{2}$ Department of Physical Therapy, Faculty of Medicine, University of Toronto, Toronto, Canada

${ }^{3}$ Sunnybrook Research Institute, Sunnybrook Health Sciences Centre, Toronto, Canada

${ }^{4}$ Department of Medical Imaging, Sunnybrook Health Sciences Centre, Toronto, Canada

${ }^{5}$ Department of Medical Imaging, Faculty of Medicine, University of Toronto, Toronto, Canada

${ }^{6}$ Division of Orthopedic Surgery, Department of Surgery, Faculty of Medicine, University of Toronto, Toronto, Canada

${ }^{7}$ Division of Orthopedic Surgery, Department of Surgery, Women's College and Mount Sinai Hospital, Toronto, Canada

${ }^{8}$ Division of Orthopedic Surgery, Department of Surgery, Sunnybrook Health Sciences Centre, Toronto, Canada

*Corresponding author: Helen Razmjou, Holland Orthopedic and Arthritic Centre, 43 Wellesley Street East, Toronto, Ontario,

Canada

\begin{abstract}
Purpose: There is minimal information on predictive value of strength-related clinical tests in detecting rotator cuff (RC) tear size and tendon reparability of large and massive tears. The purpose of this diagnostic study was to examine the validity of four strength-related clinical sign/tests in relation to RC tear size and reparability.

Methods: This was a prospective blinded study of consecutive patients with a full thickness RC tear who underwent a repair. The magnetic resonance imaging (MRI) and arthroscopic surgery were used as the gold standards.

Results: Eighty-five patients, 50 males (59\%), age 65, SD=10 completed the study. There were 60 (71\%) minor tears (small/ moderate) and 25 (29\%) major tears (large/massive) with $70(82 \%)$ patients achieving a full repair. The Jobe test had a sensitivity of $93 \%$ and $88 \%$ and a negative likelihood ratio (LR) of 0.16 and 0.27 for tendon reparability and tear size respectively. The dropping sign, hornblower sign and lift-off test had poor sensitivity $(<60 \%)$ and high specificity $(>98 \%)$ values with large positive LRs for tear size detection and tendon reparability. The validity indices in relation to MRI findings were similar to surgical findings.

Conclusion: A negative Jobe test accurately ruled out the presence of a major tear, significant supraspinatus fatty infiltration and a need for partial repair. The dropping and hornblower signs and lift off test were highly specific and when positive, they confirmed the presence of a major tear, fatty infiltration in the corresponding muscle and difficulty achieving a full repair.
\end{abstract}

Keywords: Accuracy; Shoulder, Rotator Cuff Tear; Tendon Reparability; Validity

Level of Evidence: Level I, Prospective diagnostic study

\section{Introduction}

Rotator cuff (RC) pathology is a significant cause of visits to general practitioners [1]. The direct cost of imaging, conservative treatment, surgical repair $[2,3]$ and indirect costs of impact on employment, income loss, missed workdays, and disability payments [4-6] have made this pathology an expensive 
musculoskeletal condition. Many of these costs could be avoided, in particular imaging costs, through early clinical detection and appropriate early management. This highlights the important role of the clinical examination in achieving the initial diagnosis. Unfortunately, difference in testing positions, diverse criteria used for positive test results and variability in reference standards impact the interpretation of the clinical tests' measurement properties.

While pain provocation tests have shown poor performance characteristics in confirming pathology due to low specificity, clinical tests or signs that are based on weakness and represent the integrity of specific muscles tend to have better specificity [7-12]. The most commonly used strength-related clinical examination tests or signs for pathology in supraspinatus, infraspinatus, teres minor and subscapularis muscles are the Jobe test [13], dropping sign [14], hornblower sign [15] and the lift-off test [16] respectively.

The majority of previous studies related to these clinical tests have examined their ability to detect the presence of a RC tear with minimal research existing on tear size detection [17-19]. To date, we are not aware of studies that have examined the value of these clinical tests in relation to tendon reparability which is affected by tear size, fatty infiltration and tendon quality. The initial concept of partial versus full repair was first introduced by Burkhart and colleagues approximately two decades ago [20-22]. The goal of the partial repair in patients with large/massive tears is to bring back the torn tendon to the tuberosities without excessive tension and to restore the humeral head force couple and fulcrum and improve the overall shoulder kinematics [20-22].

The increasing body of literature on large and massive tears and partial repairs in recent years [21,24-26] warrants examining strength-related clinical tests in relation to tear size and tendon reparability. Establishing the relationship between clinical examination and these factors will expedite care pathways, reduce unnecessary health care visits and improve the clinical decision-making process. The primary objective of this study was therefore to examine the validity of four clinical examination sign/tests in estimating rotator cuff tear size and determining tendon reparability. The secondary objective was to examine the value of these clinical tests in relation to pathological changes in the corresponding muscles (associated tear, atrophy and fatty infiltration). The Magnetic Resonance Imaging (MRI) and arthroscopic surgery were used as the gold standards.

\section{Material and Methods}

\section{Participants}

This prospective blinded diagnostic study was conducted at a tertiary shoulder center where consecutive surgical candidates for rotator cuff repair were examined. Inclusion criteria included pain and functional disability for more than 6 months which had failed non-operative treatment and presence of a full-thickness rotator cuff tear diagnosed on MRI and later confirmed by surgery.
Exclusion criteria included previous shoulder surgery on the affected side, presence of an active work-related shoulder injury, infection, avascular necrosis or frozen shoulder. Informed consent was obtained from all individual participants included in the study.

\section{Clinical Examination}

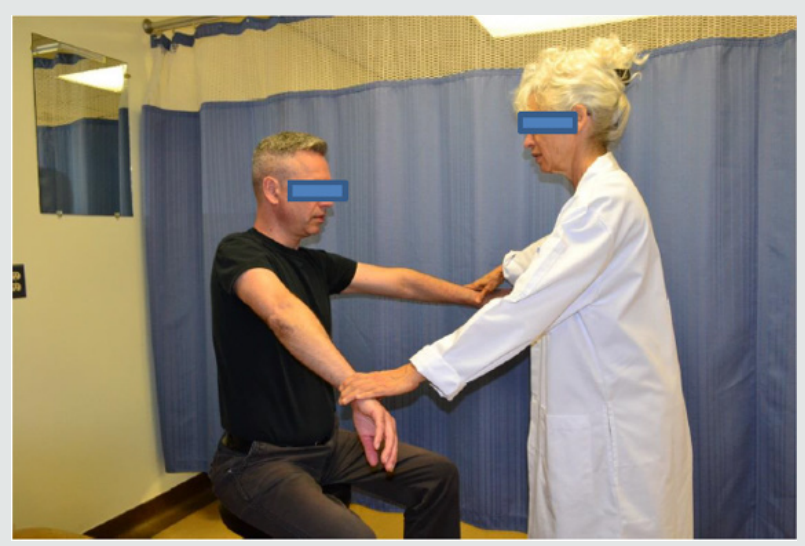

Figure 1: Operational definition of the Jobe Test.

This test was conducted at $90^{\circ}$ of the scapular plane elevations with the thumb down. The outcomes were documented as negative when the patient reported no pain or pain without weakness and positive when weakness was detected $(<5 / 5$ manual muscle testing) with or without pain.
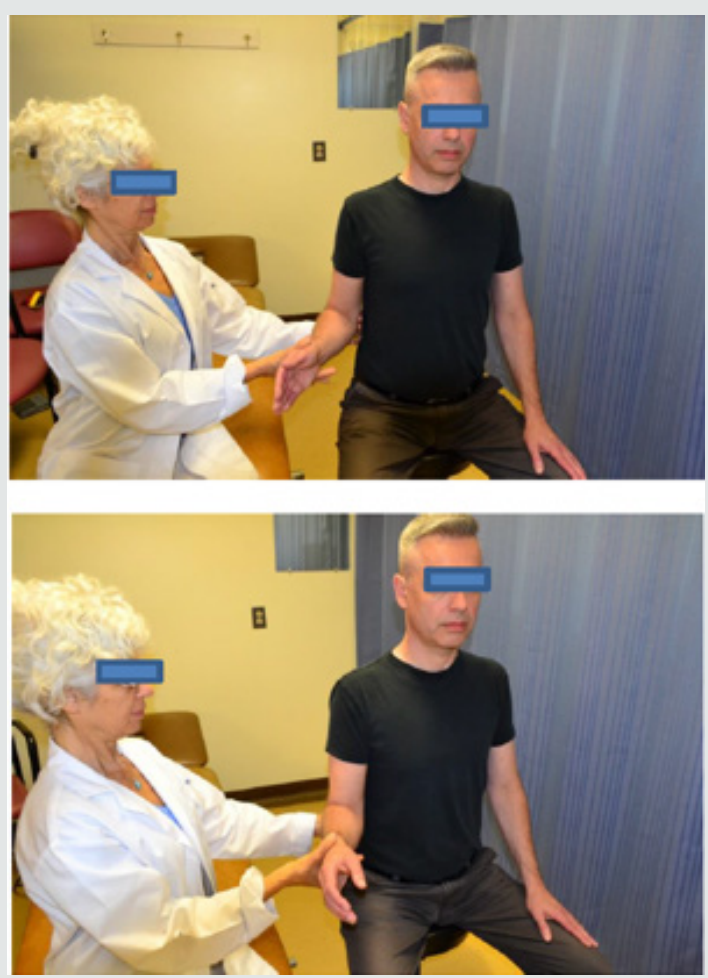

Figure 2: Operational definition of the Dropping sign.

The patient was asked to push against the examiner's hand while maintaining the elbow at $90^{\circ}$ and shoulder at $45^{\circ}$ of external rotation position. The outcomes were documented as positive when the forearm was dropped back to neutral position. 


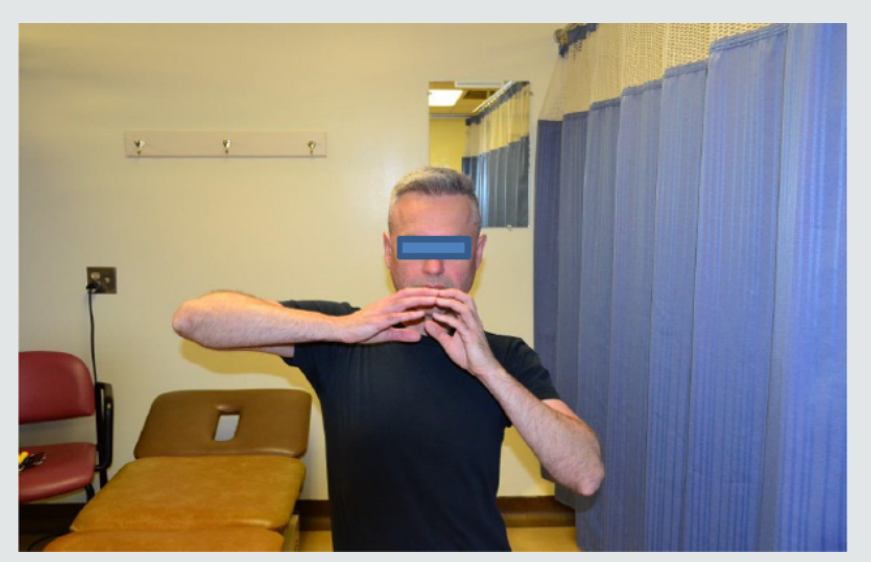

Figure 3: Operational definition of the Hornblower sign.

This sign involved observing the patient while bringing both hands to the mouth. The outcomes were documented as negative when the patient was able to externally rotate the arm in abduction and positive when patient was not able to reach the mouth without abducting the affected arm.
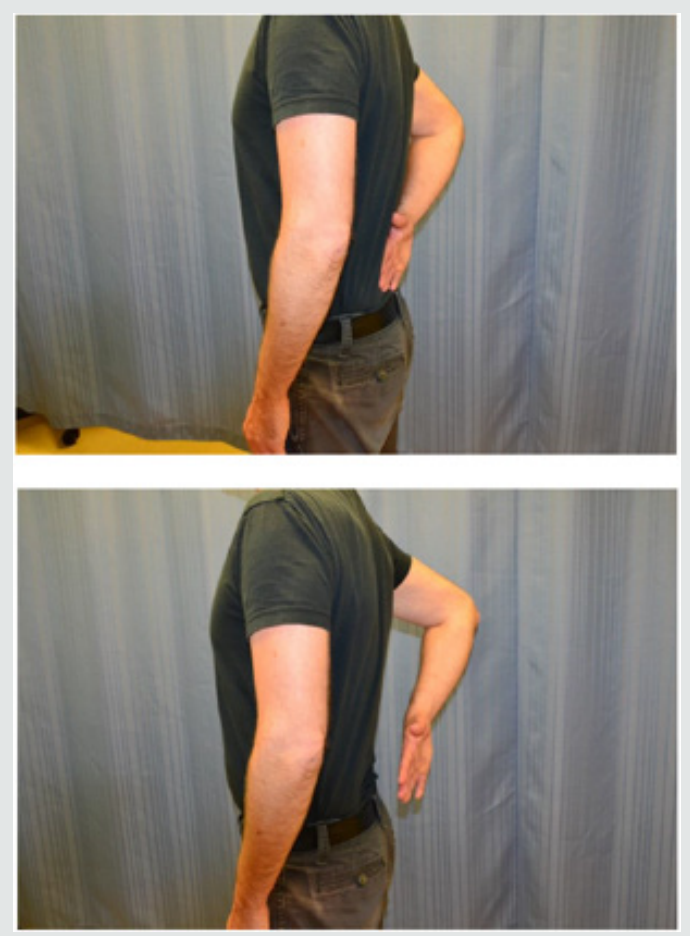

Figure 4: Operational definition of Lift off Test.

The test was conducted with the patient in standing. The ability to internally rotate to lumbar spine (waist line) was first examined. While placing the dorsum of the hand against mid-lumbar spine, the patient lifted the affected side hand away from the back. The outcomes were documented as negative when the hand was lifted away from the back. An inability to perform this task was considered a positive lift-off test.

The clinical examination was conducted 2-3 weeks prior to surgery by a physical therapist to maintain the blindness of the orthopedic surgeon and independence of the surgical findings.
The Jobe test was based on weakness using the Medical Research Council (MRC) Scale for manual muscle strength testing and was considered positive if the strength of elevation in scapular plane was less than 5 on a 5-point scale. The MRC has established reliability and validity in asymptomatic subjects and patients with musculoskeletal conditions [27]. Other tests/signs were based on observing a faulty posture (hornblower sign) or inability to initiate (lift-off test) or maintain a position (dropping sign) without examiner's interpretation of the degree of weakness. The details on testing positions and criteria for positive and negative clinical findings are presented in Figures 1-4.

\section{Predictors of Test Accuracy}

Tear size and tendon reparability were based on surgical findings. The level of fatty infiltration in rotator cuff muscles and the number of tears extending to infraspinatus or subscapularis were based on MRI imaging findings.

\section{Surgical Findings}

Surgical procedures were conducted by a senior surgeon with subspecialty in shoulder reconstruction and over 30 years of experience. With the patient in the lateral decubitus position, arthroscopic examination of the glenohumeral joint and subacromial regions were completed. The rotator cuff was repaired using marginal convergence or side to side techniques with lateral suture anchors.

The overall tear size was measured arthroscopically using a calibrated probe and classified as small $(<1 \mathrm{~cm})$, medium $(1-3 \mathrm{~cm})$, large $(3-5 \mathrm{~cm})$ and massive $(>5 \mathrm{~cm})$ based on the largest dimension [28]. For the purpose of calculating sensitivity and specificity that require binominal variables, the small and medium tears were collapsed together as minor tears and large and massive tears were collapsed as major tears.

In terms of reparability, patients were classified into two categories of full and partial repair. Full repair was either an anatomical repair or a repair to the articular margin with less than $1 \mathrm{~cm}$ residual defect. Partial repair referred to a residual defect of more than $1 \mathrm{~cm}[24]$ and was done when a full repair was not feasible.

\section{Magnetic Resonance Imaging Findings}

The majority of the MRI studies were performed internally on a 1.5-T system (General Electric Medical Systems, Milwaukee, Wis.) using a 15 platform and dedicated GE shoulder surface coil. However, all MRI images examined in this study were I.5T and the measurements were made on a PACS workstation using Agfa IMPAX software technology. All images were interpreted by a senior musculoskeletal trained radiologist with 21years of clinical experience. We examined the inter-examiner reliability of the MRI findings between the radiologist and an orthopedic surgeon (not involved in surgery of the participants) with shoulder subspecialty 
training and 10 years of clinical experience on a subsample of patients.

Presence of a full thickness tear of the supraspinatus tendon was examined on the sagittal T2 fat-suppressed images. Full thickness tears of the infraspinatus tendon were diagnosed by defining the infraspinatus muscle and musculotendinous junction on the sagittal images and following the tendon laterally to the attachment on the greater tuberosity. Teres minor and subscapularis tendons were evaluated on sagittal and axial proton-density fat-saturated images.

Fatty infiltration was documented for all muscles on the T1 sagittal image on the most lateral oblique image in which the spine is seen in contact with the scapular body as defined by Goutallier [29]. Accordingly, stage 0 corresponds to no fat, stage 1 corresponds to the muscle containing some fatty streaks, stage 2 referring to more muscle than fat, stage 3 corresponding to as much fat as muscle and stage 4 is fatter than muscle. The imaging results were specific to the muscle related to the clinical test as described in the original studies test [13-16]. For example, presence of fatty infiltration (stages 3-4 vs. stages 0-2) in supraspinatus muscle was examined against results of the Jobe test while presence of fatty infiltration in the infraspinatus muscle (stages 3-4 vs. stages 0-2) was examined in relation to the dropping and the hornblower signs as both tests are affected by the integrity of this muscle. The lift-off test was used to examine the presence of the subscapularis pathology.

\section{Statistical Analysis}

The sample size calculation was based on the estimation of the positive likelihood ratio (LRs). To detect a LR+ of 2-5, considered the least acceptable LR, a minimum sample of 70 to 79 patients was considered necessary [30].

Descriptive statistics were provided for all relevant data. The Kappa coefficient and percentage of agreement examined interexaminer reliability on MRI findings. Strength of agreement was interpreted as suggested by Landis [31]. Surgical and imaging findings were recorded for true and false positive and negatives and $2 \times 2$ tables were constructed to calculate sensitivity (Se), specificity (Sp) and likelihood ratios (LRs). The LRs which are based on both sensitivity and specificity of the test were used to determine whether a test result changed the probability of having a condition. A test with a higher LR+ has a greater value of ruling in the disease while a test with a lower value of LR- has a better predictive value of ruling out the disease. Guidelines suggested by Jaeschke et al. [32] were used for interpretation of LRs and Fagan's nomogram [33] was used to compute the approximate post-test probability based on the pre-test probability and LRs.

\section{Results}

Ninety patients consented to participate in the study. Of these patients, two were excluded at the time of surgery due to having a partial thickness rotator cuff tear, and another three patients cancelled their surgery due to personal or other medical reasons. Hence, data of 85 patients with full-thickness tear of supraspinatus, 35 females (41\%), 50 males (59\%), age 65, SD=10 were used for analysis.

Table 1: Validity indices in relation to tear size and tendon reparability.

\begin{tabular}{|c|c|c|}
\hline $\begin{array}{c}\text { Clinical Tests } \\
\text { Positive/Negative }\end{array}$ & $\begin{array}{c}\text { Tear Size } \\
\text { Minor }(\mathrm{N}=60) / \text { Major }(\mathrm{N}=25)\end{array}$ & $\begin{array}{c}\text { Tendon Reparability } \\
\text { Full }(N=70) / \text { Partial }(N=15)\end{array}$ \\
\hline \multicolumn{3}{|c|}{ Jobe Test (85) } \\
\hline $\begin{array}{l}\text { Sensitivity } \\
\text { Specificity } \\
\text { PLR } \\
\text { NLR }\end{array}$ & $\begin{array}{c}22 / 25: 0.88, \mathrm{CI}_{95 \%,}(0.69-0.97) \\
27 / 60: 0.45, \mathrm{CI}_{95 \%}(0.32-0.58) \\
1.60, \mathrm{CI}_{95 \%}(1.22-2.10), \text { Insignificant } \\
0.27, \mathrm{CI}_{95 \%}(0.09-0.80), \text { Small }\end{array}$ & $\begin{array}{c}\text { 14/15: } 0.93, \mathrm{CI}_{95 \%}(0.68-1.00) \\
\text { 29/70: } 0.41, \mathrm{CI}_{95 \%}(0.30-0.53) \\
\text { 1.58, } \mathrm{CI}_{95 \%}(1.25-2.02), \text { Insignificant } \\
0.16, \mathrm{CI}_{95 \%}(0.02-1.09), \text { Moderate }\end{array}$ \\
\hline \multicolumn{3}{|c|}{ Dropping Test (85) } \\
\hline $\begin{array}{l}\text { Sensitivity } \\
\text { Specificity } \\
\text { PLR } \\
\text { NLR }\end{array}$ & $\begin{array}{c}\text { 8/25: } 0.32, \mathrm{CI}_{95 \%}(0.14-0.50) \\
\text { 59/60: } 0.98, \mathrm{CI}_{95 \%}(0.91-0.99) \\
\text { 19.20, } \mathrm{CI}_{95 \%}(2.53-145.59), \text { Large } \\
0.69, \mathrm{CI}_{95 \%}(0.53-0.91), \text { Insignificant }\end{array}$ & $\begin{array}{c}\text { 8/15: } 0.53, \mathrm{CI}_{95 \%}(0.27-0.79) \\
\text { 69/70: } 0.99, \mathrm{CI}_{95 \%}(0.92-1.00) \\
\text { 37.33, } \mathrm{CI}_{95 \%}(5.04-276.60), \text { Large } \\
\text { 0.47, } \mathrm{CI}_{95 \%}(0.28-0.81), \text { Small }\end{array}$ \\
\hline \multicolumn{3}{|c|}{ Hornblower Sign (85) } \\
\hline $\begin{array}{l}\text { Sensitivity } \\
\text { Specificity } \\
\text { PLR } \\
\text { NLR }\end{array}$ & $\begin{array}{c}\text { 9/25: } 0.36, \mathrm{CI}_{95 \%}(0.18-0.57) \\
\text { 59/60: } 0.98, \mathrm{CI}_{95 \%}(0.91-1.00) \\
\text { 21.60, } \mathrm{CI}_{95 \%}(2.89-161.64), \text { Large } \\
0.65, \mathrm{CI}_{95 \%}(0.48-0.87), \text { Insignificant }\end{array}$ & $\begin{array}{c}\text { 9/15: } 0.60, \mathrm{CI}_{95 \%}(0.35-0.85) \\
\text { 69/70: } 0.99, \mathrm{CI}_{95 \%}(0.92-1.00) \\
\text { 42.00, } \mathrm{CI}_{95 \%}(5.75-307.05), \text { Large } \\
\text { 0.41, } \mathrm{CI}_{95 \%}(0.22-0.75), \text { Small }\end{array}$ \\
\hline \multicolumn{3}{|c|}{ Lift Off Test $(\mathrm{N}=63)^{*}$} \\
\hline $\begin{array}{l}\text { Sensitivity } \\
\text { Specificity } \\
\text { PLR/ } \\
\text { NLR }\end{array}$ & $\begin{array}{c}\text { 5/16: } 0.31, \mathrm{CI}_{95 \%}(0.11-0.59) \\
47 / 47: 1.00, \mathrm{CI}_{95 \%}(0.92-1.00) \\
\mathrm{N} / \mathrm{A} \\
0.69, \mathrm{CI}_{95 \%}(0.49-0.96), \text { Insignificant }\end{array}$ & $\begin{array}{c}\text { 5/9: } 0.56, \mathrm{CI}_{95 \%}(0.21-0.86) \\
\text { 54/54: } 1.00, \mathrm{CI}_{95 \%}(0.93-1.00) \\
\text { N/A } \\
0.44, \mathrm{CI}_{95 \%}(0.21-0.92), \text { Small }\end{array}$ \\
\hline
\end{tabular}




\section{CI: Confidence interval}

\section{PLR: Positive Likelihood Ratio,}

NLR: Negative Likelihood Ratio

Exact CI were reported for sensitivity/specificity tables that had cell<5.

*The lift-off test was performed on 63 patients who had a full range of internal rotation.

N/A: Likelihood ratios could not be calculated when sensitivity or specificity were $100 \%$

Range of LRs: LRs $>10$ or $<0.1$ (large); LRs of 5-10 and 0.2-0.1 (moderate); LRs of 2-5 and 0.5-0.2 (small); LRs of 1-2 and 0.5-1 (insignificant).

Four patients had a small tear $(<1 \mathrm{~cm}$.), 56 had a moderatesized tear (1-3cm.), 17 had a large tear ( 3 to $5 \mathrm{~cm}$ ) (7 partial and 10 full repair) and eight patients had a massive tear $(>5 \mathrm{~cm})$. Therefore, there were 60 minor tears and 25 major tears. Seven of the large tears and all eight of the massive tears could not be fully repaired. Therefore, 15 patients $(18 \%)$ had a partial repair and seventy (82\%) patients had a full repair. There were $26(31 \%)$ and $15(18 \%)$ associated full-thickness tears of the infraspinatus and subscapularis, respectively. The inter-examiner reliability was assessed between the radiologist and an orthopedic surgeon not involved in surgery. The Kappa values were $0.77(0.34-1.00)$ and $0.82(0.49-1.00)$ ranging from substantial to almost perfect agreement for fatty infiltration of supraspinatus and infraspinatus respectively. There was no tear or significant fatty infiltration in the teres minor. Table 1 shows the relationship between surgical findings (tear size and reparability) and each clinical sign/test. Table 2 shows the relationship between imaging findings (fatty infiltration, associated tears) and clinical signs/tests.

Table 2: Validity indices in relation to imaging findings.

\begin{tabular}{|c|c|}
\hline Positive clinical Tests & Imaging Findings \\
\hline Jobe test & Supraspinatus fatty infiltration \\
\hline Sensitivity & $17 / 17: 1.00, \mathrm{CI}_{95 \%}(0.80-1.00)$ \\
Specificity & $30 / 68: 0.44, \mathrm{CI}_{95 \%}(0.32-0.57)$ \\
PLR & $1.79, \mathrm{CI}_{95 \%}(1.45-2.21)$, Insignificant \\
NLR & N/A \\
\hline Dropping sign & $8 / 25: 0.32, \mathrm{CI}_{95 \%}(0.13-0.49)$ \\
\hline Sensitivity & $59 / 60: 0.98, \mathrm{CI}_{95 \%}(0.90-0.99)$ \\
\hline Specificity & $19.20, \mathrm{CI}_{95 \%}(2.53-145.59)$, Large \\
PLR & $0.69, \mathrm{CI}_{95 \%}(0.53-0.91)$, Insignificant \\
\hline NLR & $7 / 19: 0.37, \mathrm{CI}_{95 \%}(0.15-0.59)$ \\
\hline \multicolumn{2}{|c|}{ Infraspinatus fatty infiltration } \\
\hline Sensitivity & $64 / 66: 0.97, \mathrm{CI}_{95 \%}(0.93-1.00)$ \\
Specificity & $12.16, \mathrm{CI}_{95 \%}(2.75-53.75)$, Large \\
PLR & $0.65, \mathrm{CI}_{95 \%}(0.46-0.92)$, Insignificant \\
\hline NLR &
\end{tabular}

\begin{tabular}{|c|c|}
\hline Hornblower sign & Infraspinatus tear \\
\hline Sensitivity & $9 / 26: 0.35, \mathrm{CI}_{95 \%}(0.16-0.53)$ \\
Specificity & $63 / 64: 0.98, \mathrm{CI}_{95 \%}(0.91-1.00)$ \\
PLR & $22.15, \mathrm{CI}_{95 \%}(2.95-166.19)$, Large \\
NLR & $0.66, \mathrm{CI}_{95 \%}(0.50-0.88)$, Insignificant \\
\hline \multicolumn{2}{|c|}{ Infraspinatus fatty infiltration } \\
\hline Sensitivity & $7 / 19: 0.37, \mathrm{CI}_{95 \%}(0.15-0.59)$ \\
Specificity & $63 / 66: 0.95, \mathrm{CI}_{95 \%}(0.87-0.99)$ \\
PLR & $8.11, \mathrm{CI}_{95 \%}(2.32-28.36)$, Moderate \\
NLR & $0.66, \mathrm{CI}_{95 \%}(0.47-0.4)$, Insignificant \\
\hline Lift off test* & Subscapularis full cranial tear \\
\hline Sensitivity & $4 / 15: 0.27, \mathrm{CI}_{95 \%}(0.08-0.55)$ \\
Specificity & $47 / 48: 0.98, \mathrm{CI}_{95 \%}(0.89-1.00)$ \\
PLR & $12.80, \mathrm{CI}_{95 \%}(1.55-105.99)$, Large \\
\hline NLR & $0.75, \mathrm{CI}_{95 \%}(0.55-1.02)$, Insignificant \\
\hline
\end{tabular}

CI: Confidence interval

PLR: Positive Likelihood Ratio

NLR: Negative Likelihood Ratio

Range of LRs: LRs $>10$ or $<0.1$ (large); LRs of 5-10 and 0.2-0.1 (moderate); LRs of 2-5 and 0.5-0.2 (small); LRs of 1-2 and 0.5-1 (insignificant)

Exact CI were reported for sensitivity/specificity tables that had cell $<5$.

*The lift-off test was performed on 63 patients who had a full range of internal rotation and due to lack of significant number of subscapularis fatty infiltrations, this component was not analyzed.

N/A: Likelihood ratios could not be calculated when sensitivity or specificity were $100 \%$.

\section{Jobe Test}

The sensitivity of the Jobe test [13] for detecting a major tear (large or massive) was relatively high at $88 \%$, LR- $=0.27$ ). However, the test was not very specific for ruling in a major tear ( $\mathrm{Sp}=45 \%$ ). This indicates that the Jobe test is helpful in ruling out a major tear when it is negative. In terms of reparability, only one false negative was seen leading to high sensitivity of $93 \%$ (LR- $=0.16$ ) which indicates a high ability of a negative Jobe test in ruling out a need for partial repair. In terms of LRs, a negative Jobe test generates a moderate change $(0.16)$ in pretest probability of having a partial repair. Using a nomogram proposed by Fagan [33], a negative likelihood ratio of 0.16 makes a significant change in the pre-test probability of $50 \%$, lowering that to a probability of $14 \%$. All patients with stage $3 / 4$ infiltration had a positive Jobe test, producing a sensitivity of $100 \%$.

\section{Dropping Sign}

The dropping sign [14] had low sensitivity for the overall tear size detection, reparability, associated infraspinatus tear and 
advanced fatty infiltration. However, the sign was highly specific indicating a low false positive rate for all the above findings (Tables $1 \& 2$ ). As an example, a LR+= of 19 for tear size detection changes the pre-test probability of $50 \%$ to approximately $96 \%$, meaning that if the clinician gives a $50 \%$ chance of having a major tear in a patient and observes a positive dropping sign, the $50 \%$ chance increases to $96 \%$, a very significant chance of there being a large/ massive tear.

\section{Hornblower Sign}

A positive hornblower sign [15] was highly related to the overall tear size, reparability, infraspinatus associated tear and advanced fatty infiltration which shows that only a very small percentage of patients with a positive hornblower sign had a minor tear size $(2 \%)$, achieved a full repair (1\%) and had stage $1 / 2$ fatty infiltration (5\%). A LR+= of 22 for presence of a major tear changes the pre-test probability of $50 \%$ to approximately $96 \%$, meaning that observing a positive hornblower sign increases a moderate pre-test probability of $50 \%$ to high post-test probability of $96 \%$. In summary, having a negative hornblower sign does not accurately rule out a major tear, but having a positive hornblower sign accurately predicts a major pathology.

\section{Lift-off Test}

The lift-off test [16] had a perfect specificity of $100 \%$ for both tear size detection and reparability and a high specificity of $98 \%$ for subscapularis full-thickness tear. The sensitivity was low for all surgical and imaging outcomes for all outcomes (e.g. tear size, reparability and subscapularis full-thickness tear, Tables 1\&2). These findings indicate that this test is helpful in clinical decision making only when it is positive.

\section{Discussion}

The primary objective of this study was to examine the ability of commonly used strength-related clinical tests in predicting reparability and tear size of the RC tendons. The concept of reparability has been gaining importance since its conception in early 1900's as the surgeons continue to face challenges in managing large and massive tears in patients with high physical demands [21,23-26]. To our knowledge, despite the significant number of validity studies and reviews [11,12,17-19,34-36], the relationship between clinical tests and tear size and particularly reparability of the tendons has not been systematically examined. The significance of the present study is providing further evidence on clinicians' ability to differentiate between minor and major tears. Costly imaging investigations that would not alter management can be avoided by simple clinical tests and signs and most importantly, achievable and realistic post-operative patient expectations can be facilitated in the presence of large and massive tears.

\section{Jobe Test}

The results of the present study indicate that a negative Jobe test helps with a successful ruling out of a major tear that may not be fully repairable. However, when positive, this test does not guide clinical management due to its low specificity. The findings of the present study are consistent with higher sensitivity and poorer specificity of this test reported by other investigators being $86 \%$ and $50 \%$ by Leroux et al. [19] $84 \%$ and $58 \%$ by Hartel et al. [17] $87 \%$ and $43 \%$ by Ioti et al. [11] $88 \%$ and $40 \%$ by Holtby and Razmjou [18] $88 \%$ and $62 \%$ by Jain et al. [37], $89 \%$ and $55 \%$ by Yuen et al. [12], and $99 \%$ and $43 \%$ by Kim et al. [35]. The LR- of 0.17 for detecting major tears from minor tears found in our study is identical with another study [18], showing the consistency of the test in ruling out large and massive rotator cuff tears.

The Jobe test was initially described to assess the supraspinatus muscle in isolation in early 1980s [13]. However, there is minimal anatomical basis for this position to select out the supraspinatus muscle. It has been shown that in addition to the supraspinatus muscle, nine other muscles including the infraspinatus, upper subscapularis, trapezius, and serratus anterior are activated during this test [38]. In addition, the Jobe test is conducted with the shoulder internally rotated which would typically aggravate any inflamed structures located in the subacromial area between the greater tuberosity and coracoacromial arc (e.g. bursitis, tendonitis, osteophytes impingement, partial and full-thickness tears) causing pain and weakness regardless of severity of supraspinatus pathology which makes the Jobe test act more like a pain provocation test rather than a strength test. The limitation of the Jobe test in activating the supraspinatus muscle in isolation lowers the value of this test in guiding management in the presence of a minor RC pathology.

\section{Dropping Sign}

The dropping sign is highly specific in predicting a major tear, advanced fatty infiltration and associated infraspinatus tear and inability to achieve a full repair. The large positive likelihood ratios direct the clinicians' pre-test probability in a significant way, assisting with the diagnosis and overall management. There is very limited published literature on this clinical sign [12,39]. In a study conducted by Walch et al. [39] in late 1998 [39], the CT arthrogram was used as the gold standard at over one year following a cuff tear. The investigators reported sensitivity and specificity of $100 \%$ for detecting stage 3 and 4 fatty infiltration. In their study, all 12 patients of the sample of 54 who had stage 3/4 fatty infiltration had a positive dropping sign and all patients $(\mathrm{N}=29)$ with stage $1 / 2$ fatty infiltration had a negative dropping test. We found a negative dropping sign in $63 \%(12 / 19)$ of our sample with stage $3 / 4$ fatty infiltrations. The co-contraction of a healthy teres minor and a larger and more diverse sample may explain some of these inconsistencies. Generally, it is unlikely that a test would have a sensitivity and specificity of $100 \%$. In such cases, distinguishing between a diseased and non-diseased is so obvious that application of a test is not necessary. More consistent with our results, Yuen et 
al. [12] reported a low sensitivity and high specificity for presence of individual tear (50\% and $88 \%$ respectively) or combined tears (44\% and 97\%) following an acute anterior dislocation. High specificity of dropping test has been noted in a recent study that has examined the strength of external rotation in a similar position as the dropping sign (45 degrees of external rotation) [40]. The authors reported that weakness of infraspinatus muscle was more significant at 45 degrees of external rotation compared to the neutral position, confirming a high specificity of the dropping sign position.

\section{Hornblower sign}

The hornblower sign was also highly specific and when positive it was associated with larger tears, infraspinatus advanced fatty infiltration and tear and inability to achieve a full repair. There is limited published literature on the accuracy of the hornblower sign. In a retrospective study by Walch et al. [39], in which the CT arthrogram was used at over one year following a cuff tear, sensitivity and specificity values of $100 \%$ and $93 \%$ were reported for detecting stage 3 and 4 fatty infiltration or complete absence of teres minor. In their study, all patients with stage $3 / 4$ fatty infiltration in the infraspinatus had a negative hornblower sign. The authors concluded that the hornblower test was specific to teres minor only and not affected by the infraspinatus pathology [39]. However, the infraspinatus involvement in shoulder elevation and external rotation has been confirmed in the literature [4144]. McMahon et al. [42] suggested that infraspinatus activity progressively increased from 0 to 90 degrees and reported that the highest level of infraspinatus muscle activity occurred during shoulder forward flexion at 90 degrees. In a study by Ha et al. [41] the infraspinatus was highly activated at external rotation with the shoulder flexed to 90 degrees. Similarly, the activity of the infraspinatus at 90 degrees of abduction has been noted by Reinold et al. [44]. Studies that have examined the pathophysiology of rotator cuff tendons have suggested that overhead shoulder injuries in young athletes are shown to affect the infraspinatus tendon more often than other rotator cuff tendons, highlighting the activity and strain of this tendon in the external rotation/abduction position [43]. More specifically, in a recent prospective study by Jain et al. [37], the sensitivity and specificity values of the hornblower test for infraspinatus tear were $17 \%$ and $96 \%$ which is consistent with our results.

\section{The Lift-off Test}

The lift-off test was highly specific in predicting a major tear, subscapularis tear and inability to achieve a full repair. The subscapularis muscle is one of the internal rotators of the shoulder joint. The hand behind back is reported to be superior to internal rotation in neutral position. Using the data of electromyography, [45] moment arms [46] and physiologic cross-sectional areas [47] the contribution of the subscapularis muscle to internal rotation strength is calculated to be approximately $50 \%$ with the arm at the side. With the arm in full internal rotation (lift off position), the contribution of this muscle increases up to almost $90 \%$.

The original study by Gerber and Krushell [16] used a sample of 162 with 16 patients having an isolated subscapularis tear. Twelve out of 16 patients had a true positive lift-off test. The other 4 patients did not complete the test. Consistent with our results, Yuen et al. [12] reported sensitivity and specificity values of $39 \%$ and $74 \%$ respectively in 49 patients following an acute anterior dislocation for presence of a full-thickness tear using ultrasonography as the gold standard. In a study by Itoi et al. [11] where the strength of the lift off test was graded, inability to lift the hand off the back against gravity had a sensitivity of $14 \%$ and specificity of $100 \%$ for subscapularis tear [11]. In a study by Leroux et al. [19] sensitivity of $0 \%$ and specificity of $61 \%$ was reported. The authors used 55 patients of whom 27 patients had a full-thickness tear (4 small, 7 medium sized and 16 large tears). We could not verify the binominal variable of surgical criteria for the lift off test in that study and it is not clear whether the authors examined the lift-off test against presence or absence of a full-thickness tear or against different tear sizes. Therefore, we cannot comment on their sensitivity of $0 \%$. Similarly, Hertel et al reported a sensitivity of $62 \%$ and specificity of 100 [17]. In a study by Naredo et al. [48] who used ultrasonography as the gold standard, a sensitivity and specificity of $50 \%$ and $96 \%$ were reported respectively for subscapularis tear [48]. All of these studies have similar results, reporting low sensitivity and high specificity for the lift-off test.

\section{General Principles of Validity Indices of Shoulder Tests}

Normally, clinical tests that are based on pain are more sensitive and less specific, while clinical tests that are based on weakness and represent the integrity of specific RC muscles tend to have better specificity and lower sensitivity [7-12]. The reason for this finding is that a sensitive test corresponds with a negative test results which helps to rule out pathology. Absence of pain with pain provocation tests rules out a cluster of pathologies under umbrella of impingement syndrome such as inflammation, tendonitis, bursitis, partial or full thickness tear. However, presence of pain does not confirm any specific pathology which affects the utility of these tests in clinical decision making as different shoulder conditions have different managements. Strength-related clinical tests have different performance characteristics. They are not very sensitive which means they are not good screening tools to rule out a specific pathology but once they are positive, they confirm the presence of pathology. This general principle is more obvious when the severity of pathology is more significant. For example, in the present study we chose large/massive tears as the positive criterion. A number of patients with a major tear presented with a negative sign/test which led to poor sensitivity for the dropping/ hornblower signs and liftoff test. However, due to low proportion of false positives, specificity and LR+ were quite significant indicating that in clinical settings similar to ours (specialty orthopedic clinics 
where the prevalence of a major tear is high) a positive sign or test directs clinicians in the right direction and guide management more effectively by confirming pathology.

\section{Conclusion}

A negative Jobe test accurately ruled out the presence of a major tear, significant supraspinatus fatty infiltration and a need for partial repair. The dropping and hornblower signs and lift off test were highly specific and when positive, they confirmed the presence of a major tear, fatty infiltration in the corresponding muscle and difficulty in achieving a full repair.

\section{References}

1. Oh LS, Wolf BR, Hall MP, Levy BA, Marx RG (2007) Indications for rotator cuff repair: A systematic review. Clin Orthop Relat Res 455: 52-63.

2. Churchill RS, Ghorai JK (2010) Total cost and operating room time comparison of rotator cuff repair techniques at low, intermediate and high-volume centers: Mini-open versus all-arthroscopic. J Shoulder Elbow Surg 19(5): 716-721.

3. Genuario JW, Donegan RP, Hamman D, Bell JE, Boublik M, et al. (2012) The cost-effectiveness of single-row compared with double-row arthroscopic rotator cuff repair. J Bone Joint Surg Am 94(15): 13691377.

4. Mather RC 3rd, Koenig L, Acevedo D, Dall TM, Gallo P, et al. (2013) The societal and economic value of rotator cuff repair. J Bone Joint Surg Am 95(22): 1993-2000.

5. Vitale MA, Vitale MG, Zivin JG, Braman JP, Bigliani LU, et al. (2007) Rotator cuff repair: An analysis of utility scores and cost-effectiveness. J Shoulder Elbow Surg 16(2): 181-187.

6. Yeranosian MG, Terrell RD, Wang JC, McAllister DR, Petrigliano FA (2013) The costs associated with the evaluation of rotator cuff tears before surgical repair. J Shoulder Elbow Surg 22(12): 1662-1666.

7. Beaudreuil J, Nizard R, Thomas T, Peyre M, Liotard JP, et al. (2009) Contribution of clinical tests to the diagnosis of rotator cuff disease: A systematic literature review. Joint Bone Spine 76(1): 15-19.

8. Hegedus EJ, Goode AP, Cook CE, Michener L, Myer CA, et al. (2012) Which physical examination tests provide clinicians with the most value when examining the shoulder? Update of a systematic review with metaanalysis of individual tests. Br J Sports Med 46(14): 964-978.

9. Hegedus EJ, Goode A, Campbell S, Morin A, Tamaddoni M, et al. (2008) Physical examination tests of the shoulder: A systematic review with meta-analysis of individual tests. Br J Sports Med 42: 80-92.

10. Hermans J, Luime JJ, Meuffels DE, Reijman M, Simel DL, et al. (2013) Does this patient with shoulder pain have rotator cuff disease? The Rational Clinical Examination systematic review. JAMA 310(8): 837-847.

11. Itoi E, Minagawa H, Yamamoto N, Seki N, Abe H (2006) Are pain location and physical examinations useful in locating a tear site of the rotator cuff? Am J Sports Med 34(2): 256-264.

12. Yuen CK, Mok KL, Kan PG (2012) The validity of 9 physical tests for fullthickness rotator cuff tears after primary anterior shoulder dislocation in ED patients. Am J Emerg Med 30(8): 1522-1529.

13. Jobe FW, Moynes DR (1982) Delineation of diagnostic criteria and a rehabilitation program for rotator cuff injuries. Am J Sports Med 10(6): 336-339.

14. Neer C (1990) In: Neer CS, (Eds.); Shoulder reconstruction. Philadelphia, etc. In: Anatomy of shoulder reconstruction. WB Saunders Company, p. 1-39.

15. Arthuis M (1972) Obstetrical paralysis of the brachial plexus. I Diagnosis
Clinical study of the initial period. Rev Chir Orthop Reparatrice Appar Mot 58(1): 124-126.

16. Gerber C, Krushell RJ (1991) Isolated rupture of the tendon of the subscapularis muscle. Clinical features in 16 cases. J Bone Joint Surg Br 73(3): 389-394.

17. Hertel R, Ballmer FT, Lombert SM, Gerber C (1996) Lag signs in the diagnosis of rotator cuff rupture. J Shoulder Elbow Surg 5(4): 307-313.

18. Holtby R, Razmjou H (2004) Accuracy of the Speed's and Yergason's tests in detecting biceps pathology and SLAP lesions: Comparison with arthroscopic findings. Arthroscopy 20(3): 231-236.

19. Leroux JL, Thomas E, Bonnel F, Blotman F (1995) Diagnostic value of clinical tests for shoulder impingement syndrome. Rev Rhum Engl Ed 62(6): 423-428.

20. Burkhart SS (1994) Reconciling the paradox of rotator cuff repair versus debridement: A unified biomechanical rationale for the treatment of rotator cuff tears. Arthroscopy 10(1): 4-19.

21. Burkhart SS, Nottage WM, Ogilvie-Harris DJ, Kohn HS, Pachelli A (1994) Partial repair of irreparable rotator cuff tears. Arthroscopy 10(4): 363370 .

22. Burkhart SS, Esch JC, Jolson RS (1993) The rotator crescent and rotator cable: an anatomic description of the shoulder's "suspension bridge". Arthroscopy 9(6): 611-616.

23. Burkhart SS, Danaceau SM, Pearce CE Jr (2001) Arthroscopic rotator cuff repair: Analysis of results by tear size and by repair technique-margin convergence versus direct tendon-to-bone repair. Arthroscopy 17(9): 905-912.

24. Holtby R, Razmjou H (2014) Relationship between clinical and surgical findings and reparability of large and massive rotator cuff tears: A longitudinal study. BMC Musculoskelet Disord 15: 180.

25. Kim KC, Shin HD, Cha SM, Kim JH (2013) Repair integrity and functional outcomes for arthroscopic margin convergence of rotator cuff tears. J Bone Joint Surg Am 95(6): 536-541.

26. Kim SJ, Lee IS, Kim SH, Lee WY, Chun YM (2012) Arthroscopic partial repair of irreparable large to massive rotator cuff tears. Arthroscopy 28(6): 761-768.

27. Cuthbert SC, Goodheart GJ Jr (2007) On the reliability and validity of manual muscle testing: A literature review. Chiropr Osteopat 15: 4.

28. DeOrio JK, Cofield RH (1984) Results of a second attempt at surgical repair of a failed initial rotator-cuff repair. J Bone Joint Surg Am 66(4): 563-567.

29. Goutallier D, Postel JM, Bernageau J, Lavau L, Voisin MC (1994) Fatty muscle degeneration in cuff ruptures. Pre- and postoperative evaluation by CT scan. Clin Orthop Relat Res (304): 78-83.

30. Hajian-Tilaki K (2014) Sample size estimation in diagnostic test studies of biomedical informatics. J Biomed Inform 48: 193-204.

31. Landis JR, Koch GG (1977) The measurement of observer agreement for categorical data. Biometrics 33(1): 159-174.

32. Jaeschke R, Guyatt GH, Sackett DL (1994) Users' guides to the medical literature. III. How to use an article about a diagnostic test. B. What are the results and will they help me in caring for my patients? The EvidenceBased Medicine Working Group. JAMA 271(9): 703-707.

33. Fagan TJ (1975) Letter: Nomogram for Bayes theorem. N Engl J Med 293(5): 257.

34. Bak K, Sorensen AK, Jorgensen U, Nygaard M, Krarup AL, et al. (2010) The value of clinical tests in acute full-thickness tears of the supraspinatus tendon: Does a subacromial lidocaine injection help in the clinical diagnosis? A prospective study. Arthroscopy 26(6): 734-742.

35. Kim E, Jeong HJ, Lee KW, Song JS (2006) Interpreting positive signs of the supraspinatus test in screening for torn rotator cuff. Acta Med Okayama $60(4): 223-228$ 
36. Miller CA, Forrester GA, Lewis JS (2008) The validity of the lag signs in diagnosing full-thickness tears of the rotator cuff: A preliminary investigation. Arch Phys Med Rehabil 89(6): 1162-1168.

37. Jain NB, Luz J, Higgins LD, Dong Y, Warner JJ, et al. (2017) The Diagnostic Accuracy of Special Tests for Rotator Cuff Tear: The ROW Cohort Study. Am J Phys Med Rehabil 96(3): 176-183.

38. Boettcher CE, Ginn KA, Cathers I (2009) The 'empty can' and 'full can' tests do not selectively activate supraspinatus. J Sci Med Sport 12(4): 435-439.

39. Walch G, Boulahia A, Calderone S, Robinson AH (1998) The 'dropping' and 'hornblower's' signs in evaluation of rotator-cuff tears. J Bone Joint Surg Br 80(4): 624-628.

40. Razmjou H, Christakis M, Dwyer T, van Osnabrugge V, Holtby R (2017) Accuracy of infraspinatus isometric testing in predicting tear size and tendon reparability: Comparison with imaging and arthroscopy. J Shoulder Elbow Surg 26(8): 1390-1398.

41. Ha SM, Kwon OY, Cynn HS, Lee WH, Kim SJ, et al. (2013) Selective activation of the infraspinatus muscle. J Athl Train 48(3): 346-352.

42. McMahon PJ, Debski RE, Thompson WO, Warner JJ, Fu FH, et al. (1995) Shoulder muscle forces and tendon excursions during glenohumeral abduction in the scapular plane. J Shoulder Elbow Surg 4(3): 199-208.
43. Muto T, Inui H, Ninomiya $H$, Tanaka H, Nobuhara K (2017) Characteristics and Clinical Outcomes in Overhead Sports Athletes after Rotator Cuff Repair. J Sports Med (Hindawi Publ Corp) 2017: 5476293.

44. Reinold MM, Wilk KE, Fleisig GS, Zheng N, Barrentine SW, et al. (2004) Electromyographic analysis of the rotator cuff and deltoid musculature during common shoulder external rotation exercises. J Orthop Sports Phys Ther 34(7): 385-394.

45. Greis PE, Kuhn JE, Schultheis J, Hintermeister R, Hawkins R (1996) Validation of the lift-off test and analysis of subscapularis activity during maximal internal rotation. Am J Sports Med 24(4): 589-593.

46. Kuechle DK, Newman SR, Itoi E, Niebur GL, Morrey BF, et al. (2000) The relevance of the moment arm of shoulder muscles with respect to axial rotation of the glenohumeral joint in four positions. Clin Biomech (Bristol, Avon) 15: 322-329.

47. Veeger HE, Van der Helm FC, Van der Woude LH, Pronk GM, Rozendal RH (1991) Inertia and muscle contraction parameters for musculoskeletal modelling of the shoulder mechanism. J Biomech 24(7): 615-629.

48. Naredo E, Aguado P, De Miguel E, Uson J, Mayordomo L, et al. (2002) Painful shoulder: Comparison of physical examination and ultrasonographic findings. Ann Rheum Dis 61(2): 132-136.
This work is licensed under Creative Commons Attribution 4.0 License

To Submit Your Article Click Here:

Submit Article

DOI: $10.32474 /$ OSMOAJ.2019.02.000141

$\begin{gathered}\text { Orthopedics and Sports Medicine } \\ \text { Open Access Journal }\end{gathered}$
Assets of Publishing with us
- Global archiving of articles
- Immediate, unrestricted online access
- Rigorous Peer Review Process
- Authors Retain Copyrights
- Unique DOI for all articles

